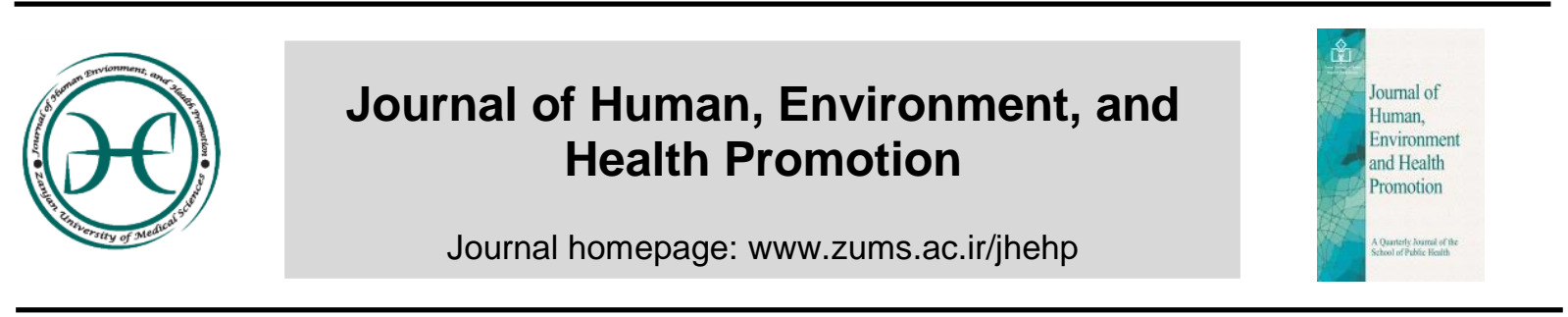

\title{
The Use of Herbal Extracts and Essential Oils as a Potential Antimicrobial in Meat and Meat Products: A Review
}

\author{
Majid Aminzare ${ }^{a, *}$, Mohammad Hashemi ${ }^{\text {, }}$, Hassan Hassanzad Azara, Jalal Hejazic \\ ${ }^{a}$ Department of Food Safety and Hygiene, School of Public Health, Zanjan University of Medical \\ Sciences, Zanjan, Iran. \\ ${ }^{b}$ Department of Nutrition, Faculty of Medicine, Mashhad University of Medical Sciences, Mashhad, \\ Iran. \\ ${ }^{c}$ Department of Biochemistry and Nutrition, Faculty of Medicine, Zanjan University of Medical \\ Science, Zanjan, Iran.
}

*Corresponding author: E-mail address: m.aminzare@zums.ac.ir

\section{A R T I C L E I N F O}

Article history:

Received November 1, 2015

Accepted December 8, 2015

Article Type:

Review Article

DOI: $10.29252 /$ jhehp.1.2.63

Keywords:

Essential oil

Extract

Antimicrobial

Meat product
A B S T R A C T

Meat and meat products are highly prone to microbial deterioration since they are rich in essential nutrients and perishable in nature and if they are not properly preserved, public health problems may occur. Recently, in order to increase the microbial quality of meat and meat products, novel ingredient systems that are associated with natural and organic foods, are applied. Many studies have demonstrated the antimicrobial activity of plant-origin natural antimicrobials in meat and meat products. Nevertheless, advanced technologies can improve the microbial stability and the sensory quality of meat products containing natural extracts and essential oils through different techniques. This paper first reviews the microbial deterioration of meat and meat products and their traditional storage techniques and then discusses the manner and extent of the use of herbal extracts and essential oils in these products.

\section{Introduction}

In recent years, manufacturers of meat products have encountered a growing demand in consumers for better-quality and healthier meat products, especially for fully natural, less processed and ready-touse products with precise labeling of additives. These products may contain natural and organic components and no preservatives to cause the regular allergic reactions [1]. Meat and meat products are rich in nutrients and spoiling substances and are thus highly prone to microbial contamination. In general, most fresh meat and meat products have a water activity (aw) higher than 0.85 and a $\mathrm{pH}$ close to the range of $\mathrm{pH}$ needed by the spoilage bacteria to survive in the meat [2]. The improper storage and processing of these

To cite: Aminzare M, Hashemi M, Hassanzad Azar H, Hejazi J. The Use of Herbal Extracts and Essential Oils as a Potential Antimicrobial in Meat and Meat Products: A Review. J. Hum. Environ. Health Promot. 2016; 1(2):63-74. 
products can therefore cause a quality deterioration and involve public health risks. [3-4].

Various meat and meat product spoilage epidemics with different degrees of severity occur every year in different parts of the production chain, such as in the preparation, storage and distribution of products. In addition to lipid oxidation and autolytic enzymatic spoilage, microbial deterioration also plays a major role in the process of quality deterioration; this process can then lead to substantial economic and ecological damage [2].

The microorganisms predominantly involved in the spoilage of meat and meat products include Pseudomonas, Acinetobacter, Brochothrix thermosphacta, Lactobacillus spp., enterobacter, molds and yeasts, which have negative effects on the taste, odor and ultimate quality of the product. Moreover, in recent years, foodborne diseases have caused economic and health problems in several different countries. Food-borne diseases are not restricted to a certain age group or country [5]. An estimated 76 million cases of foodborne diseases are reported in the US every year, 325,000 of which get hospitalized and 5000 of which are ultimately fatal [5$6]$. These cases lead to the incurrence of huge medical costs, estimated at 6.6 to 37.1 billion dollars in the US alone [5, 7].

The improper storage and processing of meat and meat products leads to diseases caused by various microorganisms such as Clostridium spp., Salmonella spp., Campylobacter jejuni, Escherichia coli, $\mathrm{O}_{157}: \mathrm{H}_{7}$, Listeria monocytogenes and Aeromonas hydrophila. Vegetative microorganism cells are destroyed in heattreated meat products (such as the Bologna sausage, known in Europe as a Lyoner) during the heating process; however, these processes do not destroy the spores of pathogenic bacteria such as Bacillus and Clostridium spp. present in foods. Spores are able to survive and do not become inactive until worse conditions emerge. In the absence of competing microflora, spores germinate and grow in favorable conditions and cause the spoilage of cooked products. Using other barriers such as storage at a low temperature and the use of more efficient preservatives is therefore vital to preventing this problem [8]. During the past years, multiple synthetic additives have been used to prolong refrigerated storage [9], which is the most common method of storing meat and meat products [4]. Various studies have shown that synthetic additives cause different carcinogenic and toxic changes, which have led to consumers' growing concern and desire to use healthier meat products containing natural instead of synthetic preservatives [1]. Natural additives are also required to improve the quality of meat products without leaving any undesirable residue [10].

\section{Microorganisms responsible for deterioration of meat and meat products}

Various microorganisms can cause spoilage of meat and meat products and serious poisoning. [3-4, 11]. Bacteria, followed by molds and yeasts, are mainly to blame for the spoilage of meat and meat products and diseases caused by their consumption. 
Pseudomonas, Acinetobacter, Brochothrix thermosphacta bacteria, Moraxella, enterobacter, Lactobacillus spp., Leuconostoc spp, Brochothrix spp., molds and yeasts are the main spoilage microorganisms. The proliferation of these microorganisms in large quantities decays meat and meat products and deteriorates their quality [3, 12], possibly due to the deterioration of the products' proteins and fats and the resulting bad odor and flavor, discoloration, inappropriate texture, gas production, sludge and change in $\mathrm{pH}[2$, 13].

Spoilage microorganisms do not normally cause disease unless consumed in large quantities and thus upsetting the gastrointestinal tract. The degree of spoilage in these products depends on a number of factors, including hygiene, storage temperature and acidity [2].

Russell et al. (1995) proposed that the best $\mathrm{pH}$ conducive to the growth of spoilage bacteria in meat and meat products is between 5.5 and 7 [14].

Another study reported the most common and serious pathogens isolated from meat and meat products to include Campylobacter jejuni, Salmonella serotype Typhimurium, Escherichia coli $\mathrm{O}_{157}: \mathrm{H}_{7}$, other intestinal Enterohemorrhagic Escherichia coli (EHEC), Listeria monocytogenes, Arcobacter butzleri, Mycobacterium avium subsp.

Paratuberculosis and Aeromonas
hydrophila [15]. The microbial
deterioration of meat and meat products
therefore counts as a major limitation in
this industry, and proper storage is

essential for producing products with the highest quality [3].

\section{Conventional storage methods preventing from microbial deterioration in meat and meat products}

The growing modern-day consumer's demand for cooked, refrigerated and readyto-use meat products has forced producers to combat the many challenges of meeting this demand, including the microbial deterioration of the products [11]. Many factors affect the consumer acceptance and longevity of fresh meat products, including microbial proliferation, color and lipid oxidation, which should be controlled in order to manufacture products with the highest quality and degree of safety [1617]. Various thermal and non-thermal storage methods are used either alone or in combination to prevent or reduce the proliferation of spoilage and pathogenic microorganisms in meat and meat products $[12,15]$.

In general, storage methods such as refrigeration and freezing provide lowerthan-optimal temperatures for microbial growth and can thus prevent the growth and proliferation of microorganisms and reduce the rate of decay $[2,18]$. Moreover, the water activity (aw) of meat and meat products can be controlled through methods such as drying or the addition of chemicals or a combination of these two, thereby preventing the growth and proliferation of microorganisms. Salt is usually added to meat products for the same purpose [2]. Cell structure modification in high pressure processing and some of its combinations, such as cell walls, ribosome and enzymes, contribute effectively to the inactivation of spoilage 
and pathogenic bacteria [19]. Radiation can also alter the genetic structure and thereby the normal functioning of the cell and destroy it.

Various meat and meat product packaging methods exist that function mainly through controlling the microenvironments of microorganisms and thus limiting their growth and proliferation. Thermal storage methods such as commercial heating and microwave heating tend to generally stop the growth and proliferation of microorganisms or else inactivate the pathogenic microflora. Chitosan is also used in the composition of anti-microbial films and affects gram positive or gram negative bacteria, molds and yeasts. Through creating a positive charge on the cell surface, Chitosan causes leakage in the cell membrane [20]. A wide range of synthetic additives are also used in the meat production industry to prevent the growth and proliferation of spoilage and pathogenic microorganisms, leading to further longevity of the product at refrigerator temperature ranges $[4,9,21]$.

The synthetic additives often used in the meat production industry include chloride, sulfate, nitrate, lactic acid, ascorbic acid and sorbic acid [2]. Certain commercial storage techniques such as maturation and fermentation have become challenging due to consumers' growing demand for lowsalt products, which has led to the industry's growing need for more efficient meat storage techniques [22]. Meanwhile, due to their carcinogenic and toxic effects on health, the use of certain synthetic additives such as nitrate salt is still a controversial issue. Some countries have restricted or banned the use of harmful additives [23]. Modern-day consumers therefore prefer to use natural additives rather than synthetic ones [1, 4, 21-22].

The focus of research has thus shifted to finding natural food additives with a wide range of antimicrobial properties and potentially improving the quality and longevity of meat products [3].

\section{Antibacterial effects of herbal extracts and essential oils on meat and meat products}

Only a few food preservatives currently used still contain herbal extracts and essential oils; however, larger amounts of these natural substances are required to produce similar effects in foods compared to when examined under in-vitro conditions. For instance, for one type of sausage, the concentration of herbal essential oil required to produce similar effects as synthetic additives is 10 times higher [24-25]. The herbal essential oils of oregano, rosemary, thyme, clove, lemon balm, ginger, coriander and marjoram have so far shown better antimicrobial effects in meat and meat products compared to other plants [3-4, 11, 26-30]. Many studies have been conducted on the aromatic chemical compounds extracted from plants and effective on spoilage and pathogenic microorganisms present in meat and meat products. Many of these tests have demonstrated the positive effects of these compounds on meat and meat products [23], particularly the effect that they have as a natural agent on spoilage and pathogenic bacteria [31]. 
The main factors that can affect the antibacterial activity of essential oils in meat and meat products include proteins and fats, water, antioxidants, $\mathrm{pH}$, salt, and external factors such as temperature, packaging and microorganism characteristics [24, 25]. According to Reglero et al. (2008), the addition of essential oils in sufficient concentrations and as a complement does not alter the odor, taste and color characteristics of food products [32]. However, the addition of high concentrations of herbal essential oils and extracts to food products for their antimicrobial and antioxidant properties may cause negative sensory changes in the food [33].

In general, bacterial sensitivity to the antibacterial effects of extracts and essential oils increases with the drop of $\mathrm{pH}$, oxygen and temperature. At a low $\mathrm{pH}$, the hydrophobicity of essential oils increases, enabling them to easily dissolve in the lipid layer of the bacterial cell membrane. Moreover, high levels of fat and protein in food products such as meat products protect bacteria against herbal essential oils, since essential oils dissolved in the lipid phase of food products have a smaller effect on the bacteria present in the water phase of the product. The lower water content of food model products compared to In vitro conditions helps prevent the progress of antibacterial agents toward the target area in the bacterial cell.

Carbohydrates provide reportedly less bacterial protection compared to lipids and proteins [24- 25].

\section{Mechanisms of the antibacterial effects of herbal extracts and essential oils}

Various studies have investigated the mechanisms of the antibacterial effects of the phenolic compounds present in herbal extracts and essential oils; however, given the large number of chemical compounds in these extracts, their antibacterial effects cannot be attributed to a specific mechanism; rather, these extracts and essential oils serve different purposes in bacterial cells. These mechanisms do not act in isolation; instead, some are affected by the others [24]. The potential antibacterial mechanisms of essential oils and extracts include mainly:

1- The effects exerted by phenolic compounds, which depend on their concentrations; at low concentrations, phenols act by affecting enzymatic activity, particularly the activity of energyproducing enzymes; at high concentrations, these compounds cause protein denaturation.

2- Changes in the permeability of microbial cells and ultimately the loss of the macro compounds in essential cellular molecules such as ribosome and sodium glutamate.

3- Interference in the normal activity of the cell membranes (electron transfer, nutrient exchange, protein synthesis, nucleic acids and enzymatic activity) and changes in the structure and functioning of the membrane [34]. 
Among the main properties of essential oils and their constituents is hydrophobicity, which enables the permeation of these essential oils in the bacterial cell membrane lipids and the mitochondria, thereby impairing their structure and causing further permeability,

which then causes the leakage of ions and other cell content. Although this limited leakage is tolerable for the bacteria, it affects their bio-viability, and the leaking of large amounts of the cell content or ions and essential molecules causes cell death $[24,35]$.

\section{Factors affecting the antimicrobial properties of herbal extracts and essential oils}

Antimicrobial properties depend a lot on factors such as the geographical location and climatic conditions of cultivation, harvest season, environmental stresses in the region and the type of extraction. For instance, savory essential oil has higher antimicrobial activities during the flowering season. These factors change the biological characteristics of essential oils through changing the type and amount of their chemical compounds [34]. In general, the higher amount of phenolic compounds in an essential oil, the higher will be its antibacterial properties against food pathogens. These compounds include Carvacrol, Eugenol and Thymol; Similar to other phenolic compounds, the mechanisms of effect of these compounds may also include disrupting the cytoplasmic membrane, disrupting the proton electromotive force and coagulation of the cell content [24-25]. The chemical structure of extracts or essential oils also affects their mechanisms of effect. The presence of the hydroxyl group is vital to phenolic compounds such as Carvacrol and Thymol. The relative position of the hydroxyl group in the phenolic ring has little effect on its antibacterial properties.

For instance, Thymol has the same antibacterial effect on Bacillus cereus, Staphylococcus aureus and Pseudomonas aeruginosa as that of Carvacrol. In one study, however, Carvacrol and Thymol were found to have different effects on gram positive and gram negative species of bacteria. The composition of the essential oils also affects the proteins in the cell membrane [24].

Most studies on the antimicrobial effects of essential oils and extracts have been limited to In vitro bacteria culture media and very few have focused on their application in the food industry [34].

Furthermore, due to their interaction with the compounds in foods, the effectiveness of essential oils and extracts is higher in culture media than in actual food products. Factors such as $\mathrm{pH}$, fat and protein, water activity (aw), temperature, the presence of other preservatives, and even physical properties and type of packaging affect the effectiveness of the essential oil in the food model. In meat products, the amount of fat contained in the product has a huge effect on the effectiveness of the extract, and high levels of fat reduce the antimicrobial effects of essential oils against most microorganisms.

Overall, the concentration of extract used in food products is higher than the concentration used for samples under in- 
vitro conditions; for instance, it is 10 times higher in the case of pork liver sausage, 50 times in soups and 25-100 times in soft cheeses. On the other hand, using high concentrations of extracts and essential oils in meat and meat products leads to adverse organoleptic changes. To avoid this issue, combination methods (combination of the extract and essential oil with other antimicrobial compounds or non-thermal storage methods), encapsulation of essential oils and the addition of the extracts and essential oils to edible antimicrobial films are highly preferred these days $[24,36]$.

\section{Gram negative and gram positive bacterial sensitivity to essential oils}

The majority of studies conducted on the effect of herbal extracts and essential oils on spoilage organisms and pathogens in food products support the claim that these substances have a slightly greater effect on gram positive than on gram negative bacteria [24]. The lower sensitivity of gram negative bacteria to the essential oils' antibacterial effects may be due to the external membrane of the cell wall in this group of bacteria, which limits the permeation of the hydrophobic components of extracts into the bacterial cell. In some exceptional cases, the sensitivity of gram positive bacteria has not been higher; for instance, Aeromonas hydrophila is highly sensitive to essential oils. Moreover, some extracts and essential oils such as oregano, clove and cinnamon have equal antimicrobial effects on both bacteria groups [24].
Each component of an extract and essential oil acts in different degrees against gram positive or gram negative bacteria. The chemical compounds in extracts and essential oils obtained from a specific plant species may be different depending on the geographical region or stage of harvest from which they have been taken. The difference in the effects of these essential oils and extracts on gram negative and gram positive bacteria may be due to the changes in their chemical compounds.

Extracts and essential oils are an aromatic mixture of volatile lipophilic compounds, which include phenolic and terpene compounds, aliphatic alcohols, aldehydes, ketones, acids and isoflavonoids. The most important antimicrobial compounds in extracts and essential oils include carvacrol, thymol, citral, eugenol and their precursors. Studies on the chemical compounds in extracts and essential oils have demonstrated that plants with a high percentage of compounds such as citral (lemon and Myrtle), eugenol (pepper, clove, bay and cinnamon) and cinnamic aldehyde (cinnamon) have stronger antimicrobial effects [34, 36-37].

Among gram negative bacteria, pseudomonads have the lowest sensitivity to the antimicrobial effects of extracts and essential oils [24].

\section{Conclusion}

Meat and meat products are seriously affected by microbial deterioration and their quality and safety are threatened with improper manipulation and storage. Many chemical compounds derived from plants 
can be effectively used along with synthetic additives in meat and meat products as natural antimicrobial substances. The main agents responsible for the antimicrobial properties of herbal extracts are phenolic compounds such as carvacrol, thymol and eugenol; however, the application of these natural extracts is limited by their intense scent, which can have adverse sensory effects on the product. Modern technologies that can be used to improve the microbial and sensory quality of meat and meat products include the encapsulation of extracts in nanoemulsions and their application as part of the hurdle technology (together with Modified Atmosphere Packaging [MAP], EDTA, Nisin, Lysozyme, etc). Extracts and essential oils are added directly to the meat batter used to manufacture meat products for their antimicrobial effects.

\section{Reference}

1. Mariutti LR, Nogueira GC, Bragagnolo N. Lipid and Cholesterol Oxidation in Chicken Meat are Inhibited by Sage But not by Garlic. J Food Sci. 2011; 76(6): 909-15.

2. Dave D, Ghaly AE. Meat Spoilage Mechanisms and Preservation Techniques: a Critical Review. Am J Agric Biol Sci. 2011; 6(4): 486-510.

3. Fratianni F, De Martino L, Melone A, De Feo V, Coppola R, Nazzaro F. Preservation of Chicken Breast Meat Treated with Thyme and Balm Essential Oils. J Food Sci. 2010; 75(8): 528-35.
4. Solomakos N, Govaris A, Koidis P, Botsoglou N. The Antimicrobial Effect of Thyme Essential Oil, Nisin and their Combination against Escherichia Coli O157:H7 in Minced Beef During Refrigerated Storage. Meat Sci. 2008; 80: 159-66.

5. Tauxe RV, Doyle MP, Kuchenmüller T, Schlundt J, Stein CE. Evolving Public Health Approaches to the Global Challenge of Foodborne Infections. Int $J$ Food Microbiol. 2010; 139: 16-28.

6. Mead PS, Slutsker L, Dietz V, McCaig LF, Bresee JS, Shapiro C, Griffin PM, Tauxe RV. Food-Rlated Illness and Death in the United States. Emerg Infect Dis. 1999; 5(5): 607.

7. Buzby J, Roberts T. ERS Updates U.S. Foodborne Disease Costs for Seven Pathogens. Food Rev.1996; 19: 20-5.

8. Cousin MA. Spore Forming Bacteria in Foods. Student Research Projects in Food Science, Food Technology and Nutrition. College of Agriculture, Ohio State University. 1989. Available form: http://www.math.unl.edu/wjump/Center1/L abs/Sporeforming\%20Bacteria\%20in\% 20Foods.pdf.

9. Chen C, Pearson AM, Gray JI. Effects of Synthetic Antioxidants (BHA, BHT and PG) on the Mutagenicity of IQ-like compounds. Food Chem. 1992; 43(3): 17783. 
10. Simitzis PE, Deligeorgis SG, Bizelis JA, Dardamani A, Theodosiou I, Fegeros K. Effect of Dietary Oregano Oil Supplementation on Lamb Meat Characteristics. Meat Sci. 2008; 79(2): 217-23.

11. Dzudie T, Kouebou CP, Essia-Ngang JJ, Mbofung CM. Lipid Sources and Essential Oils Effects on Quality and Stability of Beef Patties. J Food Eng. 2004; 30; 65(1): 67-72.

12. Lucera A, Costa C, Conte A, Del Nobile MA. Food Applications of Natural Antimicrobial Compounds. Front Microbiol. 2012; 3(287): 1-13.

13. Borch E, Kant-Muermans ML, Blixt Y. Bacterial Spoilage of Meat and Cured Meat Products. Int J Food Microbiol. 1996; 33(1):103-20.

14. Russell SM, Fletcher DL, Cox NA. Spoilage Bacteria of Fresh Broiler Chicken Carcasses. Poult Sci. 1995; 74(12): 2041-7.

15. Mor-Mur M, Yuste J. Emerging Bacterial Pathogens in Meat and poultry: an Overview. Food Bioproc Tech. 2010; 3(1): 24-35.

16. Karabagias I, Badeka A, Kontominas MG. Shelf Life Extension of Lamb Meat Using Thyme or Oregano Essential Oils and Modified Atmosphere Packaging. Meat Sci. 2011; 88(1): 109-16.
17. Mastromatteo M, Lucera A, Sinigaglia M, Corbo MR. Combined Effects of Thymol, Carvacrol and Temperature on the Quality of Non-Conventional Poultry Patties. Meat Sci. 2009; 83(2): 246-54.

18. Zhou GH, Xu XL, Liu Y. Preservation Technologies for Fresh Meat-A Review. Meat Sci. 2010; 86(1): 119-28.

19. Kerry JP, Kerry JF, Ledward D. Meat Processing: Improving Quality. Elsevier. 2002.

20. Siripatrawan U, Noipha S. Active Film from Chitosan Incorporating Green Tea Extract for Shelf Life Extension of Pork Sausages. Food Hydrocoll. 2012; 27(1): 102-8.

21. Govaris A, Solomakos N, Pexara A, Chatzopoulou PS. The Antimicrobial Effect of Oregano Essential Oil, Nisin and their Combination against Salmonella Enteritidis in Minced Sheep Meat During Refrigerated Storage. Int $J$ Food Microbiol. 2010; 137(2): 175-80.

22. Hyldgaard M, Mygind T, Meyer RL. Essential Oils in Food Preservation: Mode of Action, Synergies, and Interactions with Food Matrix Components. Front Microbiol. 2012; 3(12): 1-24.

23. Samojlik I, Lakic N, Mimica-Dukić N, Đaković-Svajcer K, Bozin B. Antioxidant and Hepatoprotective Potential of Essential 
Oils of Coriander (Coriandrum Sativum L.) and caraway (Carum carvi L.)(Apiaceae). J Agric Food Chem. 2010; 58(15): 8848-53.

24. Burt S. Essential Oils: Their Antibacterial Properties and Potential Applications in Foods - a Review. Int $J$ Food Microbiol. 2004; 94(3): 223-53.

25. Bagamboula CF, Uyttendaele $\mathrm{M}$, Debevere J. Inhibitory Effect of Thyme and Basil Essential Oils, Carvacrol, Thymol, Estragol, Linalool and P-Cymene Towards Shigella Sonnei and S. Flexneri. Food Microbiol. 2004; 21(1): 33-42.

26. Barbosa LN, Rall VL, Fernandes AA, Ushimaru PI, da Silva Probst I, Fernandes $\mathrm{Jr}$ A. Essential Oils against Foodborne Pathogens and Spoilage Bacteria in Minced Meat. Foodborne Pathog Dis. 2009; 6(6): 725-8.

27. Chouliara E, Kontominas MG, Singh VK, Govil JN, Ahmad K, Sharma RK. Combined Effect of Thyme Essential Oil and Modified Atmosphere Packaging to Extend Shelf-life of Fresh Chicken Meat. Nat Prod. 2007: 423-41.

28. Menon KV, Garg SR. Inhibitory Effect of Clove Oil on Listeria Monocytogenes in Meat and Cheese. Food Microbiol. 2001; 18(6): 647-50.

29. Skandamis PN, Nychas GJ. Effect of Oregano Essential Oil on Microbiological and Physico-Chemical Attributes of Minced Meat Stored in Air and Modified Atmospheres. J Appl Microbiol. 2001; 91(6):1011-22.

30. Tsigarida E, Skandamis P, Nychas GJ. Behaviour of Listeria Monocytogenes and Autochthonous Flora on Meat Stored under Aerobic, Vacuum and Modified Atmosphere Packaging Conditions with or without the Presence of Oregano Essential Oil at 5 C. J Appl Microbiol. 2000; 89(6): 901-9.

31. Bajpai VK, Baek KH, Kang SC. Control of Salmonella in Foods by Using Essential Oils: A review. Food Res Int. 2012; 45(2): 722-34.

32. Reglero G, Frial P, Cifuentes A, García-Risco MR, Jaime L, Marin FR, Palanca V, Ruiz-Rodríguez A, Santoyo S, Señoráns FJ, Soler-Rivas C. Meat-Based Functional Foods for Dietary Equilibrium Omega-6/Omega-3. Mol Nutr Food Res. 2008; 52(10): 1153-61.

33. Gutierrez J, Barry-Ryan C, Bourke P. The Antimicrobial Efficacy of Plant Essential Oil Combinations and Interactions with Food Ingredients. Int $J$ Food Microbiol. 2008; 124(1): 91-7.

34. Tiwari BK, Valdramidis VP, O, Donnell CP, Muthukumarappan K, Bourke P, Cullen PJ. Application of Natural 
Antimicrobials for Food Preservation. $J$ Agric Food Chem. 2008; 124(1): 91-7.

35. Azer AI, Kobilinsky A, Tholozan JL, Dubois-Brissonnet F. Combinations of Food Antimicrobials at Low Levels to Inhibit the Growth of Salmonella Sv. Typhimurium: A Synergistic Effect. Food Microbiol. 2005; 22(5): 391-8.

36. Tajkarimi MM, Ibrahim SA, Cliver DO. Antimicrobial Herb and Spice Compounds in Food. Food control. 2010; 21(9): 1199-218.

37. Reichling J, Schnitzler P, Suschke U, Saller R. Essential Oils of Aromatic Plants with Antibacterial, Antifungal, Antiviral, and Cytotoxic Properties-an Overview. Complement Med Res. 2009; 16(2): 79-90. 
